\title{
Exploring Transit's Contribution to Livability in Rural Communities: Case Studies of the North Dakota Cities of Valley City and Dickinson
}

\author{
Ranjit Godavarthy and Jeremy Mattson \\ North Dakota State University
}

\begin{abstract}
This paper investigates the nexus of transit and rural livability as demonstrated by case studies in the North Dakota communities of Valley City and Dickinson. While there are many factors that influence the livability of a rural community, transit is believed to be an important contributor. For each of the two North Dakota communities considered, public/resident surveys, local transit rider surveys, and stakeholder interviews were conducted to understand differing opinions on livability and how transit contributes to livability.

In both Valley City and Dickinson, surveys of residents showed that they believe affordable housing, low crime, quality healthcare, overall cost of living, quality public schools, and available jobs are the most important factors contributing to the livability of a small community. While transit was not among the top factors, survey respondents expressed considerable support for providing transit services and funding transit through various sources. Residents in both cities expressed the opinion that transit should be provided in their community as a transportation option for seniors, people with disabilities, those who choose not to drive, and those who cannot afford to drive. Transit riders in both cities indicated that transit is important to their quality of life, and stakeholders from both communities expressed the sentiment that transit is a critical lifeline for people who are elderly and/or have a disability, individuals with no vehicle, and those who cannot drive.
\end{abstract}

Keywords: transit and livability, rural livability, public transportation, demand response transit, rural community survey

\section{Introduction}

In June 2009, the US Department of Housing and Urban Development (HUD), US Department of Transportation (USDOT), and the US Environmental Protection Agency (EPA) incorporated six principles

(C) 2018 Ranjit Godavarthy \& Jeremy Mattson

http//dx.doi.org/10.5038/2375-0901.21.2.4

ISSN: 1077-291X | Licenced under Creative Commons License Attribution - Noncommercial 4.0

The Journal of Public Transportation is published by the Center for Urban Transportation Research at the University of South Florida 
of livability into federal funding programs, policies, and future legislative proposals (USDOT n.d.). These six livability principles are:

1. Provide more transportation choices.

2. Promote equitable, affordable housing.

3. Enhance economic competitiveness.

4. Support existing communities.

5. Coordinate policies and leverage investments.

6. Value community and neighborhoods.

In general, transportation facilities and public transportation agencies play a critical role in community livability and in the six livability principles. According to Transit Cooperative Research Program (TCRP) Report 22, in metropolitan areas, transit plays a powerful role in creating livable communities by creating places for community life, acting as a catalyst for downtown and neighborhood renewal, creating opportunities for entrepreneurship and economic development, improving safety and comfort, making community destinations accessible and convenient, and shaping community growth (TRB 1997). Schlossberg et al. (2013) evaluated the quality and accessibility of transit from a livability perspective and identified three policy areas where transit agencies can improve: (1) increasing service frequency for ridership, (2) clustering destinations at transit stops, and (3) providing pedestrian-friendly connectivity at the transit stop, as most transit users are pedestrians before and after the ride.

While the major idea of livability is about linking the quality and location of transportation facilities to various opportunities such as access to good jobs, affordable housing, quality schools, and safer streets and roads, most of the discussion so far has focused on urban livability, with less research on rural livability. Edrington and Brooks (2013) studied the literature relating to the connection between rural transit and rural livability and concluded that rural livability was poorly understood and that future studies with rural area residents are needed to better define livability from a rural perspective. A study conducted by Transportation for America included 12 case studies in small cities, towns, and rural regions across the country and observed that livability in a small town or city involves providing people (including seniors and those who cannot afford to drive) better travel choices throughout their region, encouraging growth in historic small-town Main Streets, and providing a high quality of life with ample green space, biking and walking paths, shopping, restaurants, and healthcare located nearby and easily accessible (Barry 2010).

In rural areas, public transportation provides critical lifeline services to transit-dependent people, connecting them to healthcare services, educational institutions, employment, and other important activities. While there are many factors that influence the livability of a rural community, transit can be an important contributor. However, this subject is under-studied and poorly represented in literature; a better understanding of transit's significance toward rural livability is needed. Some rural communities provide different kinds of public transit services, while others do not have any public transit. To investigate the nexus of transit and livability at the community level, the Texas A\&M Transportation Institute (TTI) conducted a study that reviewed literature to explore the concept of livability in rural America, developed a framework for a pilot case study, and finally conducted a case study in West Columbia, Texas (Brooks et al. 2014; 2015).

The study presented here adopts the case study framework developed by Brooks et al. (2015) and applies it to two small communities in North Dakota, Valley City and Dickinson, to investigate the nexus of transit and livability at the community level. Valley City was selected because it fits well with the criteria established in Phase 1 of the TTI study for selecting a suitable pilot case study community. While Dickinson also meets the Phase 1 criteria, it was specifically selected because it is a rapidly growing community due to the recent oil boom. Both are small cities with existing demand response transit services. 


\section{Study Objective and Methods}

The main objective of this study is to investigate the nexus of transit and livability in rural communities by examining the opinions of community residents, transit users, and transit stakeholders. The study method included conducting a series of stakeholder interviews, a resident survey, and a transit rider survey in the two communities. For each community, a total of 1,500 resident surveys were distributed by mail to a random sample of residents. Transit rider surveys were conducted in each community with coordination from the local transit manager. Further, stakeholder interviews/surveys were performed to understand their opinion of transit's contribution toward community livability. Stakeholders included agencies or organizations affected by the transit service or who have an interest in the transit service.

\section{Case Study Communities and Existing Transit Services}

Valley City has a population of 6,669 according to 2015 US Census estimates and is located in eastern North Dakota, as shown in Figure 1. It is 62 miles west of Fargo (population: 118,525), the largest city in the state, and the closest city larger than Valley City is Jamestown (population: 15,422), which is 35 miles to the west.

An analysis of American Community Survey (ACS) 2014 five-year estimates shows that Valley City has a large concentration of older adults, residents are largely middle-income, and they rely heavily on automobile transportation. About $23 \%$ of its population is aged 65 or older, while $7 \%$ is 85 years or older. By comparison, $14 \%$ of the US population is 65 or older, and just $2 \%$ is 85 or older nationally. The median household income $(\$ 50,000)$ is close to the national median $(\$ 53,482)$. The income distribution shows a smaller percentage of households earning more than $\$ 100,000$ per year (17\%), compared to the national average (23\%). However, poverty and unemployment are lower in Valley City. About $8.0 \%$ of the population is below the poverty line, compared to $15.6 \%$ nationally; the unemployment rate is $1.8 \%$ compared to $4.9 \%$ nationally. Ethnicity is predominantly white (94.8\%), with very small minority populations. About half of one percent uses public transportation to commute to work, while $70 \%$ drive alone, $17 \%$ carpool, and $8 \%$ walk.

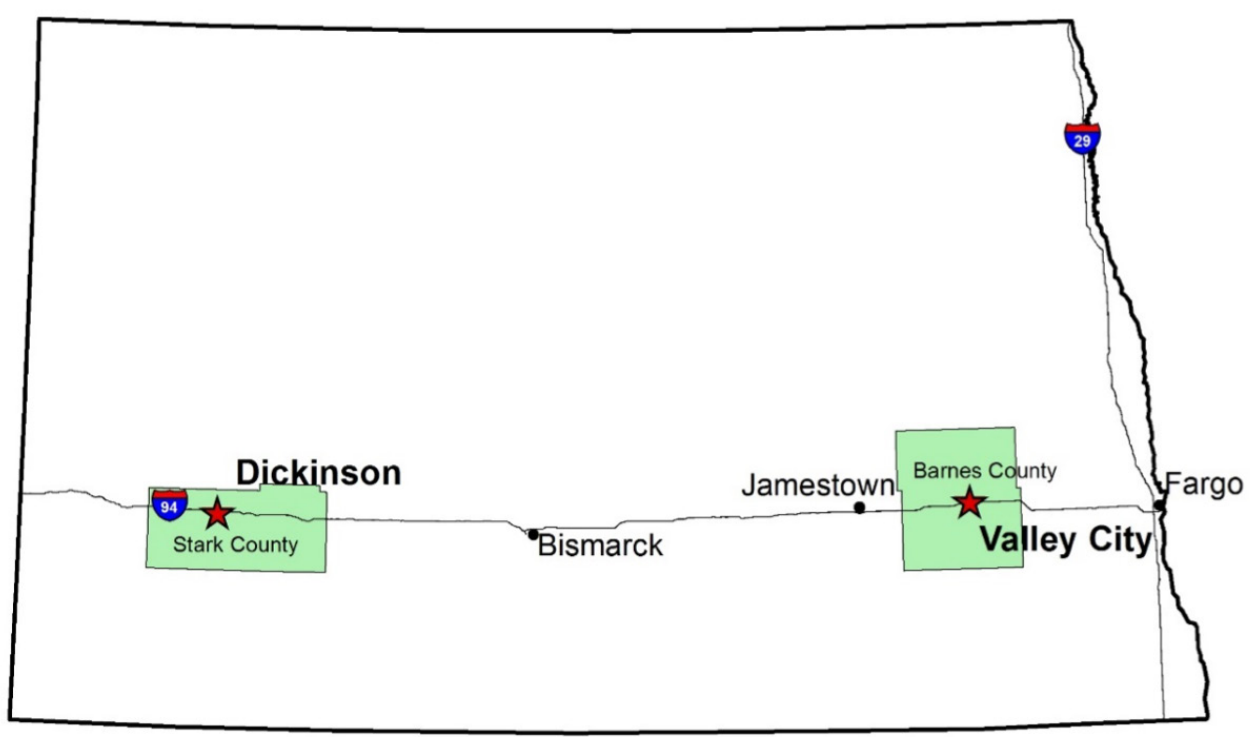

FIGURE 1.

Location of case study communities 
Valley City is served by South Central Transit, an operator that provides demand response transit services to a seven-county region in North Dakota. South Central Transit is one of the largest rural agencies in the state, providing 103,897 trips in 2015. Service is provided in Valley City Monday through Friday, 8 a.m. to 5 p.m., and Saturday and Sunday, 8 a.m. to 2 p.m., to the general public for various trip purposes, such as to and from meal sites, medical appointments, shopping, recreation, schools, and personal needs. Demand response services are offered to the general public at a cost of $\$ 2$ per person per trip in Valley City. Further, transportation options to nearby cities are provided at reasonable rates. For Valley City residents, trips to Jamestown are offered three days a week at a cost of $\$ 5$ per person for a round-trip. Trips to Fargo are provided Monday through Friday as needed at a cost of $\$ 10$ per person for a round-trip. South Central Transit also operates metered taxi service in Valley City 24 hours per day, seven days per week. In addition to serving the residents of Valley City, it serves residents in a number of smaller towns in Barnes County and six neighboring rural counties.

Dickinson was selected as the second case study community because it has been one of the fastest growing cities in the United States. Located in southwestern North Dakota, as shown in Figure 1, Dickinson has a population of 23,765 according to 2015 US Census estimates. In 2013, Dickinson was ranked as America's second biggest boomtown after Williston, North Dakota, with a yearly population growth rate of $6.5 \%$ because of the oil boom (Christie 2013). The population grew by $34.0 \%$ from 2010 to 2015, driven by the growth of the oil industry in western North Dakota. With a median age of 34.7, Dickinson has a higher younger population than both Valley City and the national average, which is arguably due to the oil boom attracting younger workers to the city. The city does have a significant older population ( $13.6 \%$ is 65 or older and $3.3 \%$ is 85 or older), though it is smaller in percentage terms than Valley City's. The percentage of the population aged 65 or older is similar to the national average (13.7\%), while the percentage of population 85 or older is larger than the national average (1.9\%). Median household income is much higher in Dickinson $(\$ 69,956)$ than the national median $(\$ 53,482)$, while the poverty rate $(8.1 \%)$ and unemployment rate $(1.8 \%)$ are well below average. According to 2014 ACS data, workers in Dickinson predominately drive alone to work (83.0\%), while public transportation is rarely used for such a purpose ( $0.1 \%$ of workers). Other modes of transportation to work include $11.1 \%$ carpool, $3.6 \%$ work at home, $2.1 \%$ walk, and $0.5 \%$ use taxi, motorcycle, or other modes. Similar to Valley City, the population in Dickinson is largely white (94.3\%).

Public Transit provides demand response service in the city limits to Dickinson residents Monday through Sunday, 6:30 a.m. to 10:00 p.m. The agency provided 32,380 trips in 2015. Services are offered to the general public at a cost of $\$ 4$ per person for a prescheduled trip within Dickinson city limits ( $\$ 3$ for each additional person with same pickup location and destination). Reservations must be made at least before noon on the previous day. Same-day service is also available at a cost of $\$ 8$ per person per trip ( $\$ 5$ for each additional person with the same pickup location and destination). Trips are also available beyond Dickinson city limits up to five miles at an additional cost of $\$ 1$ per mile per person. Transportation options to nearby cities are also provided at higher rates than the average per mile cost in Valley City. For Dickinson residents, trips to Bismarck are offered on Tuesdays at a cost of $\$ 37.50$ per person for a one-way trip, and $\$ 75.00$ per person round-trip. Travel to Bismarck on any other days is possible for $\$ 125$ for a round-trip and is subject to driver and vehicle availability. Public Transit also provides transportation service for any other out-of-town trips Monday through Friday with a base fare of $\$ 8$ and a $\$ 1$ charge per mile per person, again subject to driver and vehicle availability.

\section{Resident Surveys}

A total of 1,500 resident surveys were distributed in each community by mail to a random sample of residents. Mailing addresses were purchased from AccuData Integrated Marketing. The survey included an invitation/ consent letter, a survey form, and a postage-paid envelope for returning the completed form. The resident survey instrument can be found in the full technical report of the study (Godavarthy and Mattson 2016); 
however, the questions included in the survey and their analysis will be explained in detail in this paper. The invitation/consent letter also included a Web link for interested respondents to take the survey online. A total of 241 responses (228 paper and 13 online; 16\% response rate) were received in Valley City and a total of 175 responses (169 paper and 6 online; 11.6\% response rate) were received in Dickinson. Table 1 shows demographic information for the survey respondents.

\section{TABLE 1.}

Summary of Resident Survey Demographics

\begin{tabular}{|c|c|c|}
\hline Description & Valley City & Dickinson \\
\hline Returned survey responses & 241 & 175 \\
\hline Response rate (\%) & 16 & 12 \\
\hline \multicolumn{3}{|l|}{ Gender } \\
\hline Male (\%) & 52 & 57 \\
\hline Female (\%) & 48 & 43 \\
\hline \multicolumn{3}{|c|}{ How long have you lived in this city? } \\
\hline$<1$ year $(\%)$ & 2 & 1 \\
\hline $1-5$ years $(\%)$ & 8 & 12 \\
\hline $6-10$ years $(\%)$ & 10 & 5 \\
\hline $11-20$ years $(\%)$ & 13 & 14 \\
\hline$>20$ years $(\%)$ & 67 & 68 \\
\hline \multicolumn{3}{|l|}{ Age } \\
\hline $25-34(\%)$ & 5 & 16 \\
\hline $35-44(\%)$ & 12 & 15 \\
\hline 45-54 (\%) & 19 & 20 \\
\hline $55-64(\%)$ & 28 & 25 \\
\hline $65-74(\%)$ & 24 & 12 \\
\hline$\geq 75$ (\%) & 12 & 11 \\
\hline \multicolumn{3}{|c|}{ Number of vehicles in household } \\
\hline $0(\%)$ & 0.4 & 1.2 \\
\hline $1(\%)$ & 19 & 14 \\
\hline $2(\%)$ & 40 & 33 \\
\hline 3 or more $(\%)$ & 40 & 51 \\
\hline \multicolumn{3}{|c|}{ Combined annual household income } \\
\hline$<\$ 15,000(\%)$ & 4 & 4 \\
\hline$\$ 15,000-\$ 24,999(\%)$ & 11 & 1 \\
\hline$\$ 25,000-\$ 34,999(\%)$ & 12 & 2 \\
\hline$\$ 35,000-\$ 49,999(\%)$ & 11 & 10 \\
\hline$\$ 50,000-\$ 74,999(\%)$ & 21 & 12 \\
\hline$\$ 75,000-\$ 99,999(\%)$ & 16 & 25 \\
\hline$\geq \$ 100,000(\%)$ & 25 & 45 \\
\hline
\end{tabular}


In Valley City, most of the survey respondents either strongly agreed (16\%) or agreed (52\%) that they were completely satisfied with their quality of life, $13 \%$ disagreed, and $2 \%$ strongly disagreed, while the remainder had no opinion. Satisfaction levels were somewhat lower in Dickinson, where $8 \%$ agreed and $48 \%$ strongly agreed that they were completely satisfied with their quality of life, while $21 \%$ disagreed and $4 \%$ strongly disagreed.

The resident survey asked about the importance of various factors in the livability of any community. Low crime, affordable housing, overall cost of living, quality healthcare, available jobs, and quality public schools were the top six factors most often mentioned as being very important or important to residents in both Valley City and Dickinson. While these other factors were more likely to be considered important, 39\% of the survey respondents in Valley City and 30\% of those in Dickinson also considered transit as either very important or important toward livability in any US community.

When the Valley City residents were asked about the top six factors contributing to the current livability of their city, quality public schools and low crime were the top two factors, selected by more than $70 \%$ of the respondents. Overall cost of living, quality healthcare, and walkability were also mentioned by more than $50 \%$ of the respondents (Figure 2). Twenty-seven percent felt that public transit was one of the top six factors contributing to the current livability of Valley City. Though public transit was not mentioned by most of the respondents as one of the top six factors affecting community livability, responses from additional survey questions presented in the upcoming paragraphs will show the importance and support for public transit to be available in their community.

A comparison of perceptions of livability in any community versus livability in Valley City is shown in Figure 2. Factors such as quality public schools, walkability, daily commute, and public transit were perceived to be contributing more toward livability in Valley City. Further, comparatively fewer respondents felt that affordable housing, quality healthcare, and available jobs contributed toward livability in Valley City, in comparison to what is perceived to be important for any community, which means that improvement of these factors in Valley City would make it more livable.

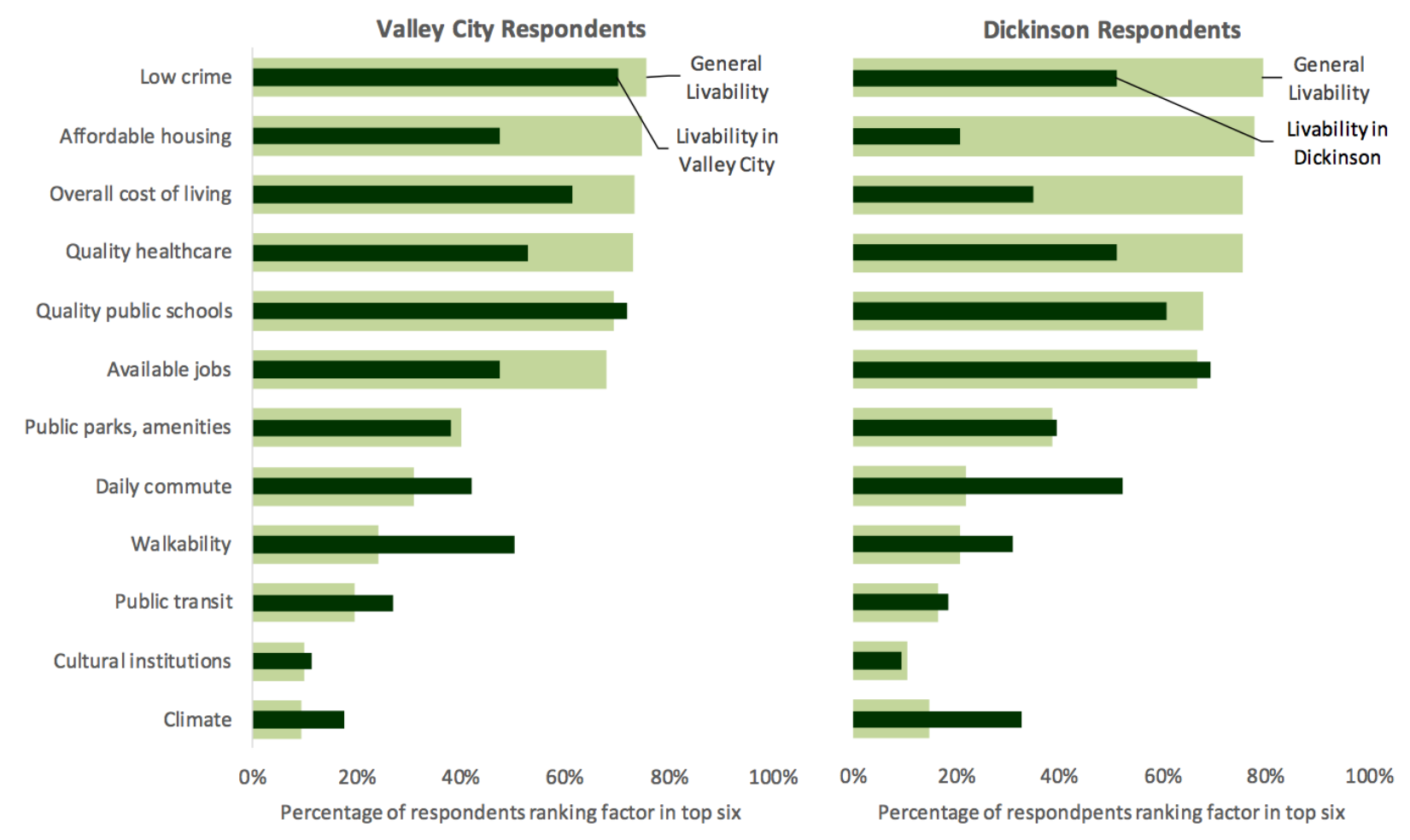

FIGURE 2.

Comparison of factors affecting livability in Valley City and Dickinson 
Following a similar explanation, factors such as available jobs, quality public schools, and daily commute were perceived to be contributing toward livability in Dickinson (Figure 2). It can be observed from Figure 2 that comparatively fewer respondents felt that affordable housing, low crime, quality healthcare, and overall cost of living contributed toward livability in Dickinson, in comparison to what is perceived to be important for any community, which means that improvement of these factors in Dickinson would make it more livable. Again, while public transit was not identified as one of the top contributors to livability, $18 \%$ of the respondents felt that public transit was one of the top six factors contributing to the current livability of Dickinson.

Responses from open-ended survey questions resulted in large shares of respondents (28\% in Valley City and $21 \%$ in Dickinson) stressing again that providing affordable housing (low-cost housing for single families and low- and medium-income seniors, low-cost entry-level housing, etc.)) would make Valley City and Dickinson even more livable. Some other improvements frequently mentioned by respondents from both cities included the following: better and more shopping options and restaurants through commercial development, more things/activities to do for both youth and adults, more quality healthcare services, lower taxes, more walking/bike paths, more street improvements, and lower cost of living. Improvements that were specifically mentioned by Valley City respondents included better job opportunities and improvements specifically mentioned by Dickinson respondents included better/more transit service and low crime. Also, some of the Dickinson respondents stated their unhappiness about the way the city has turned out due to the oil boom. Improvements that were specifically mentioned by Dickinson respondents (more transit service and low crime) might be an outcome of rapid population growth.

When asked about their awareness of local public transit service, survey respondents indicated a high level of awareness of South Central Transit in Valley City and Public Transit in Dickinson, as well as support for the service. Most of the respondents (95\% in Valley City and $90 \%$ in Dickinson) were aware of the transit service, and 22\% of Valley City and 10\% of Dickinson respondents have used the service. Further, most of the survey respondents (90\% in Valley City and 89\% in Dickinson) either strongly agreed or agreed that transit service should continue to be available for their community residents, and most either strongly agreed or agreed with using city, county, state, and federal funds for transit. According to Valley City and Dickinson residents, the most important reasons for having public transit in their community were to provide: (1) transportation options for seniors and persons with disabilities; (2) transportation options for those who choose not to drive; and (3) options for people who cannot afford to drive. See Table 2 for details and other reasons mentioned for having public transit in the study communities.

TABLE 2.

Importance of Public Transit in Valley City and Dickinson

\begin{tabular}{|r|r|r|}
\hline $\begin{array}{r}\text { Why is it important to have public transit in your } \\
\text { City? (Check up to three) }\end{array}$ & Valley City & Dickinson \\
\hline Options for seniors and persons with disabilities & $96 \%$ & $91 \%$ \\
\hline Option for those who choose not to drive & $71 \%$ & $66 \%$ \\
\hline Option for people who cannot afford to drive & $64 \%$ & $62 \%$ \\
\hline Option for saving on cost of transportation & $16 \%$ & $19 \%$ \\
\hline Reduce energy consumption and protect air quality & $10 \%$ & $11 \%$ \\
\hline Because walking is difficulty in my community & $7 \%$ & $10 \%$ \\
\hline I do not think it is important to have transit & $2 \%$ & $3 \%$ \\
\hline
\end{tabular}

Survey participants were asked if they would use transit in the future under different hypothetical situations (Figure 3). Most of the respondents agreed that they would be likely to use transit if they were no longer able to drive well due to health or other reasons. On the other hand, a minority of the respondents in 
both communities would use transit if gasoline prices increased to over $\$ 5.00$ per gallon. Nearly half of the respondents would be likely to use transit if their car broke down or was needed by someone else, or if their household income decreased significantly.

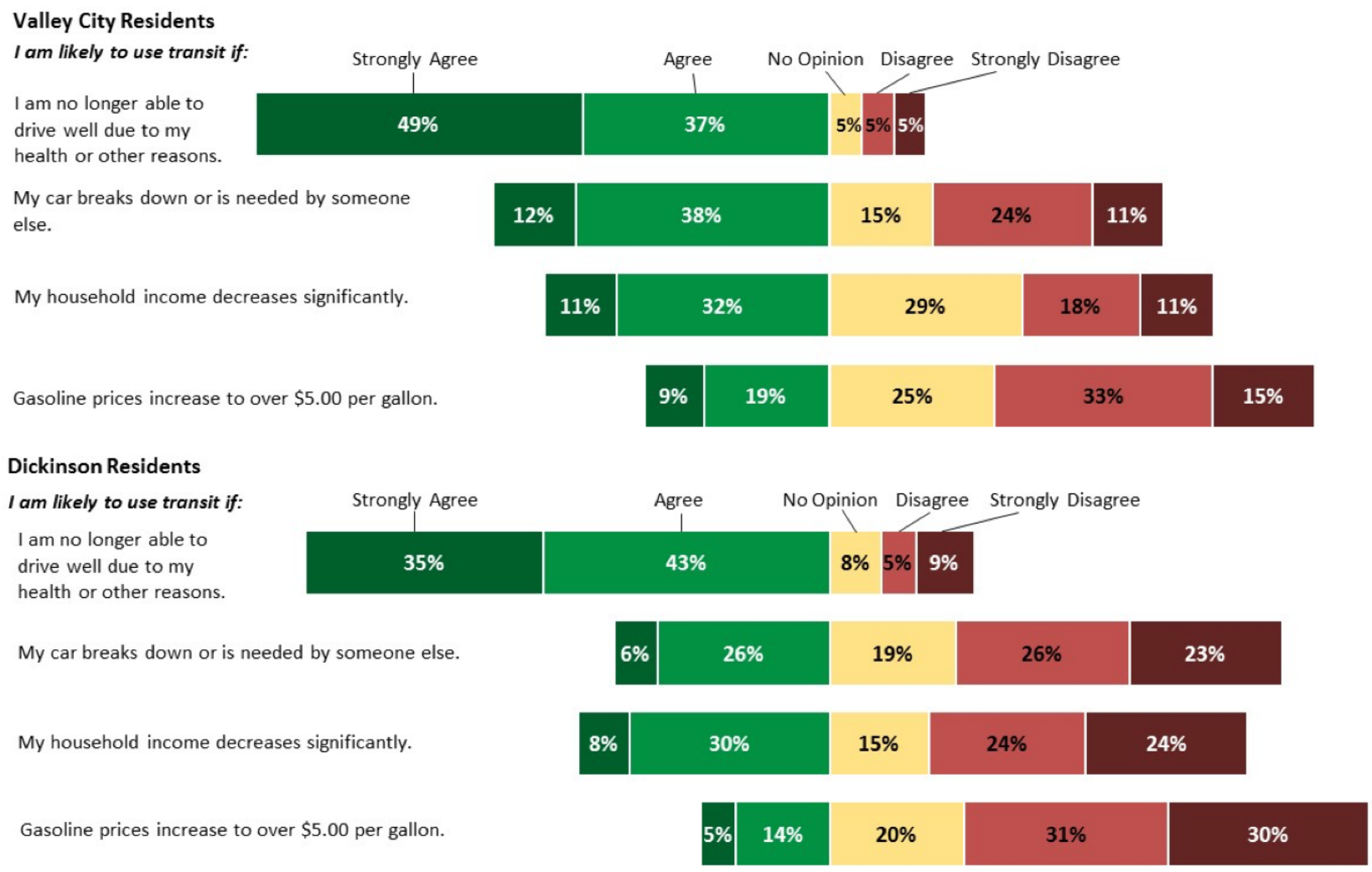

\section{FIGURE 3.}

Future use of transit under hypothetical situations

\section{Transit Rider Surveys}

In Valley City, rider surveys were distributed onboard vehicles by the vehicle operators and in Dickinson, transit rider surveys were distributed by mail using addresses obtained from the Public Transit rider database. The survey included a survey form and a postage-paid envelope for returning the completed form. Rider surveys were distributed to South Central Transit riders in Valley City for 10 days during mid-December 2015, resulting in 48 returned responses. The response rate could not be calculated because it is unknown how many riders received the survey. In Dickinson, 230 surveys were distributed by mail to Public Transit riders who had used the service within the past year, and an additional 100 surveys were handed out by vehicle operators to their riders. A total of 78 responses were received from the Public Transit rider survey, yielding a response rate of $24 \%$.

A majority of respondents ( $70 \%$ overall) were female, and many reported that they had no vehicle available in their household (34\% in Valley City and 65\% in Dickinson), that they lived alone (45\% in Valley City and 67\% in Dickinson), and that their annual household income was less than $\$ 15,000$ ( $42 \%$ for both communities; see Table 3 for more details). Many of the South Central Transit respondents were either 75 years or older (26\%) or 17 years or younger (26\%), and more than $70 \%$ of the Public Transit riders were 55 or older. Attending some 
college was the most common response to education completed by South Central Transit respondents (31\%) and high school or GED was the most common response to education by Public Transit respondents (45\%). Most respondents identified themselves as white ( $96 \%$ of South Central Transit and $89 \%$ of Public Transit riders). Six percent of Valley City and 5\% of Dickinson respondents identified themselves as Native Americans, and smaller percentages were Hispanic or Latino or black. Most (89\% of South Central Transit and $80 \%$ of Public Transit riders) either strongly agreed or agreed that transit was very important to their quality of life.

\section{TABLE 3.}

Summary of Transit Survey Demographics

\begin{tabular}{|c|c|c|}
\hline Description & Valley City & Dickinson \\
\hline Returned survey responses & 48 & 78 \\
\hline \multicolumn{3}{|l|}{ Gender } \\
\hline Male (\%) & 30 & 30 \\
\hline Female (\%) & 70 & 70 \\
\hline \multicolumn{3}{|l|}{ Age } \\
\hline$\leq 17(\%)$ & 24 & 0 \\
\hline $18-24(\%)$ & 2 & 7 \\
\hline $25-34(\%)$ & 7 & 7 \\
\hline $35-44(\%)$ & 7 & 8 \\
\hline $45-54(\%)$ & 9 & 7 \\
\hline $55-64(\%)$ & 15 & 29 \\
\hline $65-74(\%)$ & 11 & 17 \\
\hline$\geq 75(\%)$ & 26 & 26 \\
\hline \multicolumn{3}{|c|}{ Including yourself, how many people live in your household? } \\
\hline $1(\%)$ & 45 & 67 \\
\hline $2(\%)$ & 12 & 21 \\
\hline $3(\%)$ & 12 & 8 \\
\hline $4(\%)$ & 19 & 3 \\
\hline 5 or more $(\%)$ & 12 & 1 \\
\hline \multicolumn{3}{|c|}{ Number of vehicles in household } \\
\hline $0(\%)$ & 34 & 65 \\
\hline $1(\%)$ & 25 & 20 \\
\hline $2(\%)$ & 32 & 8 \\
\hline 3 or more (\%) & 9 & 7 \\
\hline \multicolumn{3}{|c|}{ Combined annual household income } \\
\hline$<\$ 15,000(\%)$ & 42 & 42 \\
\hline$\$ 15,000-\$ 24,999(\%)$ & 6 & 21 \\
\hline$\$ 25,000-\$ 34,999(\%)$ & 6 & 8 \\
\hline$\$ 35,000-\$ 49,999(\%)$ & 8 & 3 \\
\hline$\$ 50,000-\$ 74,999(\%)$ & 11 & 3 \\
\hline$\$ 75,000-\$ 99,999(\%)$ & 17 & 1 \\
\hline$\geq \$ 100,000(\%)$ & 11 & 22 \\
\hline
\end{tabular}


Respondents were asked to identify why they started riding transit (Figure 4). South Central Transit respondents most commonly answered (35\%) that they started using transit because it was convenient. The other most-selected responses were that they could no longer drive or had difficulties driving (23\%), no longer had access to a vehicle (21\%), did not like to drive in poor weather (19\%), or had a disability (17\%). Other written-in reasons mainly included providing transportation for children to attend daycare, preschool, school, and other children activities. Public Transit respondents most commonly answered that they had a disability limiting their ability to travel in other ways (44\%), they could no longer drive or had difficulties driving (38\%), they no longer had access to a vehicle (32\%), and they could not get a ride from others or did not want to (28\%).

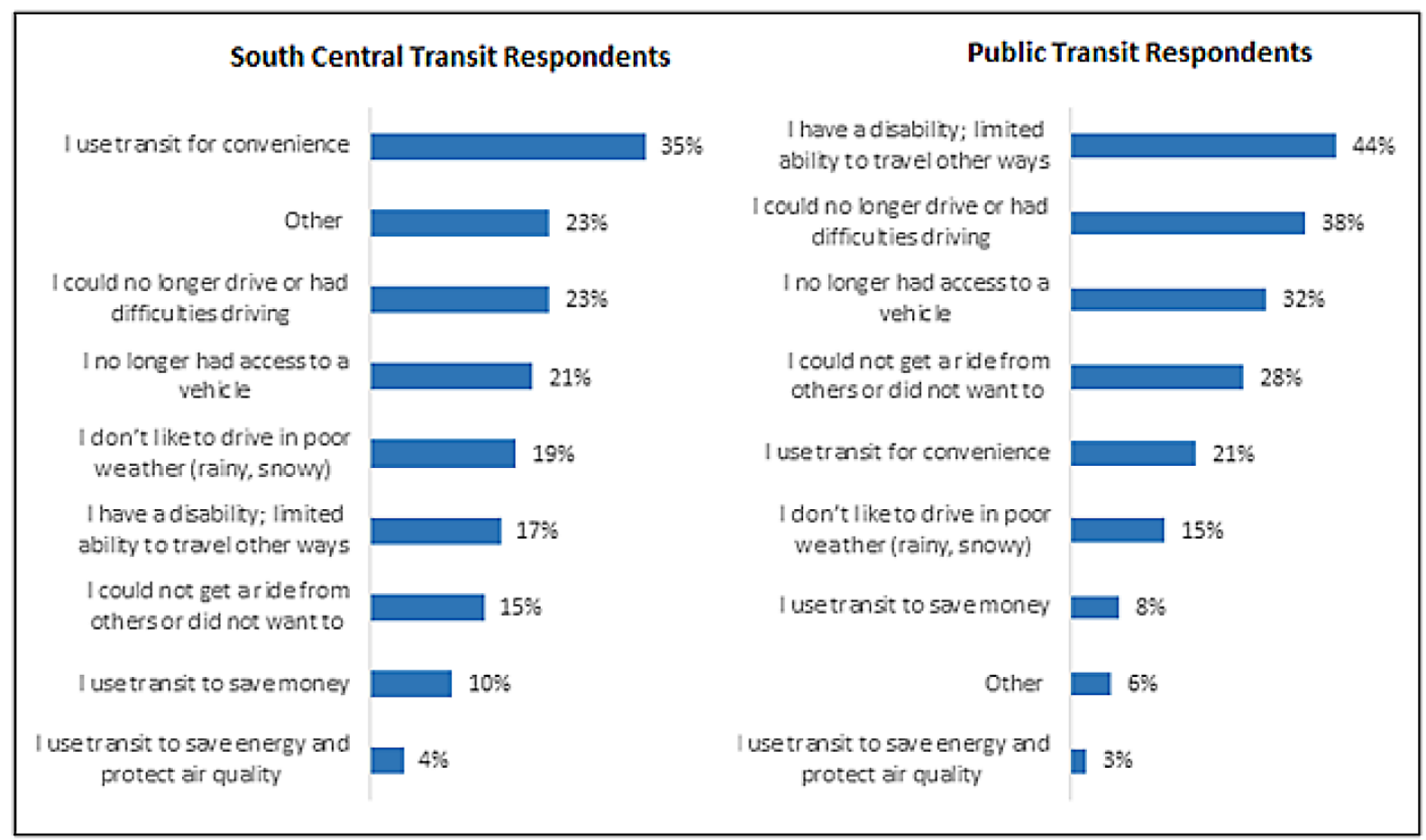

\section{FIGURE 4.}

Reasons South Central Transit and Public Transit users began using the service

More than $80 \%$ of the South Central Transit survey respondents and about half of Public Transit users were regular riders (rode at least two days per week). The top two trip purposes that were identified by Valley City respondents were (1) medical appointments, healthcare, dental services; and (2) school, college, job training (Figure 5 illustrates various trip purposes). In Dickinson, medical appointments/healthcare/dental services accounted for a large share of transit trips, as about two-thirds of respondents reported using the service for this purpose. The service, though, is also used for a variety of purposes including shopping, errands, work, personal business, and social trips. Eighty-one percent of transit users in Valley City and 71\% of those in Dickinson agreed that they could travel to places they needed with their current travel options. 


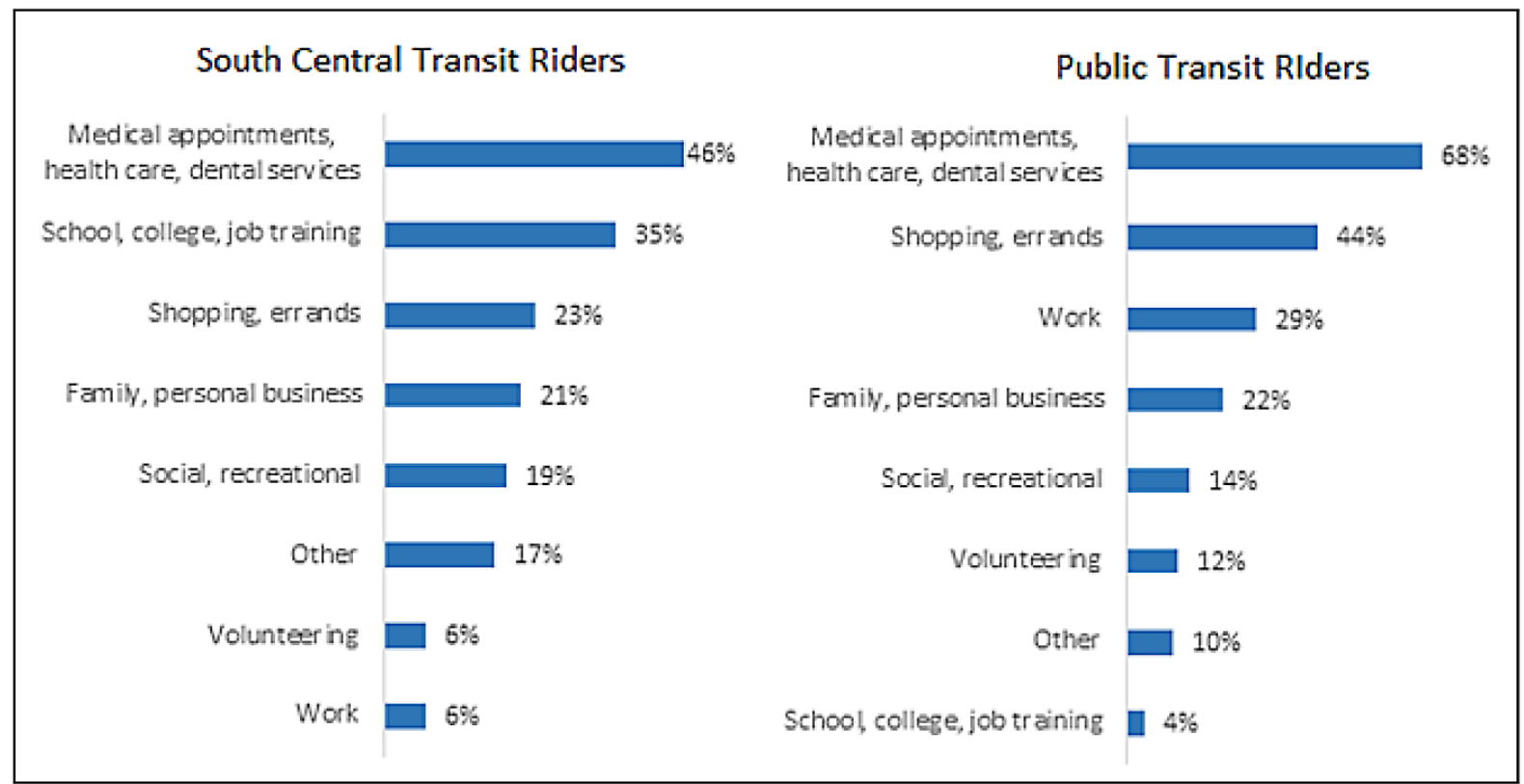

\section{FIGURE 5.}

Purposes for transit trips

When riders were asked how they would make their trips if transit were not available, some indicated that they would find other ways, but many would not be able to make their trips. If transit was not available, $56 \%$ of South Central Transit riders and 50\% of Public Transit riders would make the same number of trips to the places they currently travel using transit, and 7\% of South Central Transit and 11\% of Public Transit riders would not be able to make those trips. The remaining riders would make somewhat fewer trips ( $13 \%$ of South Central and $17 \%$ of Public Transit riders) or a lot fewer trips (24\% of South Central and $22 \%$ of Public Transit riders) to the places they currently travel using transit service.

\section{Stakeholder Interviews}

For conducting the South Central Transit and Public Transit stakeholder interviews, the research team gathered a list of available stakeholders and their contacts from the respective transit agency directors. Stakeholders included agencies or organizations who were affected by the transit service or who had an interest in or concern with the transit service. The research team used a set of questions to acquire comparable subject-based responses from stakeholders to understand the importance of transit to their organization and community and its contribution toward livability. A total of nine South Central Transit and eight Public Transit stakeholder interviews were conducted. Most of the responding stakeholders' organizational visions and missions linked directly with improving the livability conditions for their community by providing services such as assistance for people with disabilities or special needs, assisted living facilities, residential assistance for children and adults with disabilities, public safety, healthcare services, employment opportunities, education, and enhanced housing and social opportunities.

Most of the stakeholders from both communities felt that the local transit agency played an important role by providing travel options for their clients/customers/students/employees to reach them, go home, attend important meetings, or travel anywhere they needed to go. All stakeholders from both communities expressed 
the sentiment that the local transit agency was a critical lifeline to their community for the elderly and/or for people with disabilities, and an important transportation option for children to attend preschool and school, people who needed to travel out-of-town for dialysis or special medical treatment, individuals with no vehicle, and those who could not drive.

Core components of community livability that were frequently identified by stakeholders in Valley City and Dickinson included safety, affordable housing, quality public schools, availability of accessible public transportation, availability of jobs with good wages, quality healthcare, and recreational activities. These livability components were similar to those identified in the resident surveys.

In Valley City, most of the stakeholders felt that having South Central Transit was especially important because (1) there were a lot of seniors and people with disabilities who needed transportation services for regular activities and medical appointments; (2) the lack of proper medical services in town created a need to travel to Fargo or Jamestown for special medical services; and (3) there was a lack of private taxi services. Similarly in Dickinson, most of the stakeholders felt that having Public Transit was especially important because the city was spread out and it was difficult to travel between any two locations without some form of motorized transport, especially during extreme winters.

\section{Conclusions}

This study was aimed at better understanding rural livability factors and transit's contribution to rural livability in the North Dakota communities of Valley City and Dickinson. Most residents in both communities believed that transit should be continued and that the service should be funded using city, county, state, and federal funds. Resident survey respondents expressed the opinion that transit should be provided in their community as a transportation option for seniors and people with disabilities, those who chose not to drive, and those who could not afford to drive. Also, most of the respondents to the resident survey who were not currently using transit indicated that they would likely use transit in the future if they were no longer able to drive due to health or other reasons. Many respondents to the transit rider survey were regular riders and felt that transit was very important to their quality of life. In the absence of transit, about half of the riders would either have to make fewer trips or not be able to make the trips at all. Stakeholder interviews conducted in the two rural communities resulted in similar findings.

Overall, most residents and all stakeholders acknowledged that transit played a key role in their community livability, and transit riders were very satisfied with their current transit service and strongly agreed that transit was very important to their quality of life. Since most of the research conducted to date has focused on linking transit with urban livability, this study contributes to knowledge about factors affecting rural livability, and transit's importance to rural livability and transit riders' quality of life. Results from the study could be useful for city officials, planners, and transit operators in rural areas to better understand livability factors and transit's role while moving toward developing sustainable communities. Rural community residents' support for using city, county, state, and federal funds for transit developments can be a great resource for city officials and transit operators when requesting grants for introducing transit service, making service continuously available, or providing service improvements for rural communities. Further, the rapid growth of population and its effect on various livability factors has been measured through the Dickinson community case study; results from this case study could be useful for city officials of communities experiencing similar growth to understand its impact on various community livability factors and to plan accordingly. 
While the results from the North Dakota rural communities show that transit is very important for livability of the transit-dependent population, similar studies in various rural communities in the nation would be beneficial in understanding the larger picture of transit's contribution to rural livability in the United States.

\section{References}

Barry, S. 2010. Case Studies on Transit and Livable Communities in Rural and Small Town America. Transportation for America. Accessed August 12, 2016. http://t4america.org/wp-content/uploads/2010/09/ Livability-Transit-Rural-Case-Studies-WEB.pdf.

Brooks, J., S. Edrington, S. Sharma, S. Vasishth, and L. Cherrington. 2014. Literature Review: Transit and Livability in Rural America. Technical Memorandum 1. Texas A\&M Transportation Institute.

Brooks, J., S. Sharma, M. Pappas, and L. Cherrington. 2015. Pilot Case Study Findings and Phase 2 Case Study Outreach Plan. Technical Memorandum 3. Texas A\&M Transportation Institute.

Christie, L. 2013. "America's Biggest Boomtown: Fastest Growing Boomtowns." CNNMoney (blog). Last updated March 19, 2013. http://money.cnn.com/gallery/pf/2013/03/19/oil-boomtowns/2.html.

Edrington, S., and J. Brooks. 2013. "Connection Between Rural Transit and Rural Livability." TRB 92nd Annual Meeting Compendium of Papers 13-3290.

Godavarthy, R., and J. Mattson. 2016. Exploring Transit's Contribution to Livability in Rural Communities: Case Study of Valley City, ND, and Dickinson, ND. SURLC 16-004. Small Urban and Rural Livability Center, North Dakota State University. https://www.ugpti.org/resources/reports/downloads/surlc16-004.pdf.

Schlossberg, M., J. Dill, L. Ma, and C. Meyer. 2013. Measuring the Performance of Transit Relative to Livability. Final Report OTREC-RR-13-04. Oregon Transportation Research and Education Consortium. doi:10.15760/ trec.135.

TRB (Transportation Research Board). 1997. The Role of Transit in Creating Livable Metropolitan Communities. TCRP Report 22, Transit Cooperative Research Program.

US Census Bureau. 2015. American Community Survey. Accessed August 12, 2016. https://www.census.gov/ programs-surveys/acs/news/data-releases/2014/release.html\#par_textimage_9.

USDOT (US Department of Transportation). Federal Highway Administration. n.d. Livability in Transportation Guidebook: Planning Approaches that Promote Livability. Accessed August 12, 2016. https://www.fhwa.dot. gov/livability/case_studies/guidebook/livabilitygb10.pdf.

\section{About the Authors}

Ranjit Godavarthy (ranjit.godavarthy@ndsu.edu) is an assistant professor of transportation at the Upper Great Plains Transportation Institute (UGPTI) at North Dakota State University. He received a PhD in Civil Engineering from Kansas State University. His research interests include public transportation in small urban and rural areas, bikeshare research, highway safety, low volume road (LVR) safety, roundabout studies, pedestrian studies, and freight transportation.

Jeremy Mattson (jeremy.w.mattson@ndsu.edu) is an associate research fellow at UGPTI. He received a PhD in Transportation and Logistics at North Dakota State University. His research interests include rural and small urban transit, mobility and transportation needs of older adults and people with disabilities, travel behavior, transit demand modeling, rural intercity transportation, and transportation economics. 